\title{
"Viver é influenciar" \\ Mário Magalhães, sanitarismo desenvolvimentista e o \\ campo intelectual da saúde pública (1940-1960)*
}

José Roberto Franco Reis

"A pobreza é causa da enfermidade e a enfermidade origina maior pobreza em um círculo vicioso. Por conseguinte, a saúde pública é um problema que está relacionado intimamente com o progresso econômico e social que se alcança em uma coletividade". Essa frase do sanitarista Edward A. Winslow (1955, p. 110), pronunciada durante a v Assembleia Mundial da Saúde, realizada em Genebra e promovida pela recém-criada Organização Mundial da Saúde (OMS) em maio de 1952, expressa bem o clima que se instala no plano internacional em torno das necessidades de formulação e aplicação de políticas de saúde pública, vale dizer, da direção e da orientação que doravante deveriam ser seguidas para que se atingisse outro patamar de realizações sanitárias. Trata-se de uma estratégia de ação alicerçada no pressuposto que se tornou uma espécie de ideia-força do período: o círculo vicioso da pobreza e da doença - a pobreza produzindo doença e a doença produzindo mais pobreza, em um processo de retroalimentação com amplitude descendente ou crescente. Tal fato consolidou a perspectiva de que a saída dessa situação - a possibilidade de superação do quadro crítico da saúde pública - só se efetivaria por intermédio de uma aposta decidida no desenvolvimento e no progresso econômico.

No entanto, tal pressuposição não gerava um sentido único e uniforme, resultando em olhares razoavelmente atravessados, ainda que potencialmente convergentes. Com efeito, daí emergiram tanto defensores da ideia de que a partir da implantação de uma moderna infraestrutura de saúde, de uma ade- 
1. O Sesp foi criado em 1942 por meio de uma acordo assinado entre Brasil e Estados Unidos como parte de um processo de aproximação entre os dois países no contexto da Segunda Guerra Mundial, tendo em vista os interesses norte-americanos em torno da borracha na região do Vale Amazônico. Seu objetivo inicial era cuidar do saneamento nessa região, notadamente no que diz respeito ao controle da malária, além de outras funções menores (treinamento de profissionais de saúde - médicos, enfermeiros e engenheiros sanitários - e colaboração com o Serviço Nacional de Lepra). Logo ampliou suas atividades e começou a atuar na região do Vale do Rio Doce por ser uma importante área mineradora (Campos, 2000, p. 207). Com o fim da Segunda Guerra, permaneceu no Brasil e ampliou muito suas funções e área de atuação.

2. O nome completo do sanitarista era Mário Magalhães da Silveira, mas, como aponta Sarah Escorel (2000, p. 12), era de fato conhecido por Mário Magalhães (e seu irmão, que também era médico, por Fausto Silveira). Sendo assim, neste texto, inclusive no seu título, será frequentemente dessa forma que o referido sanitarista será apresentado e referenciado. quada educação sanitária e de mais conhecimentos e profissionais técnicos e qualificados "se poderia resolver os problemas sanitários, aumentar o nível de produtividade do trabalho, vencer a pobreza e conquistar o desenvolvimento" (Campos, 2006, p. 262), como teses que salientavam quase o processo inverso: desenvolvimento, com prosperidade econômica e social, seria precondição para melhorias gerais nas condições de saúde. Nesse último caso, investimentos excessivos em saúde, além de custosos, por si só não trariam resultados proporcionais em termos sanitários, ainda que ações médicas básicas possibilitassem condições mínimas indispensáveis para até mesmo inserir determinado país na rota do progresso e do desenvolvimento, este, sim, prioritário e fundamental.

No Brasil, tais teses são basicamente exemplificadas nas visões que até certo ponto defendiam os sanitaristas ligados ao Serviço Especial de Saúde Pública $(\text { Sesp })^{1}$ e seus aliados no Ministério da Saúde - propositores de elevados investimentos em saúde como forma de enfrentar os problemas sanitários e assim propiciar crescimento e prosperidade - e nas concepóes dos adeptos da corrente que se convencionou chamar de sanitarismo desenvolvimentista, na qual, de modo inverso, consideravam o desenvolvimento econômico e social do país condição necessária e prévia para a melhoria da situação geral de saúde, dentre os quais se destacam as figuras dos médicos Mário Magalhães da Silveira², Carlos Gentile de Mello e Samuel Pessoa. Ademais, uma série de outras posições contrastantes tem sido atribuída à visão dos sespianos e seus aliados e à dos sanitaristas desenvolvimentistas. Entre elas, com destaque, há a orientação campanhista dos primeiros, caracterizada por intervenções centralizadas, verticais e definidas em função do combate a certas doenças específicas, e a perspectiva dos segundos, que consideravam a implantação de "políticas de saúde horizontais e permanentes voltadas para a prevenção" (Idem, p. 264), ou seja, descentralizadas (municipalizadas) e integradas.

Nosso objetivo neste texto é, justamente, problematizar alguns desses antagonismos. Para tanto, observamos as possíveis linhas de continuidade ou descontinuidade entre os diferentes momentos de afirmação do pensamento sanitarista, tendo em vista nossa discordância em relação à compreensão mais corrente que identifica um processo, se não de ruptura, com certeza de polarização plena, sem maiores mediações e interlocuções, entre o modelo de saúde formulado desde o movimento sanitário dos anos de 1920 e consolidado no primeiro governo Vargas, que permanece com força nos anos seguintes, de 1945 a 1964, identificado como sanitarismo campanhista, e o chamado sanitarismo desenvolvimentista, que se estrutura sobretudo dos anos de 1950 em diante. Com efeito, o que se pretende mostrar aqui é que, 
para além dos pontos inequivocamente divergentes, salientados por uma importante parte da literatura (Escorel, 2000; Braga e Paula, 1981; Teixeira, 1988) e reforçados pelo antagonismo explícito de Mário Magalhães ao Sesp, é possível identificar alguns aspectos razoavelmente convergentes; ou seja, ao mesmo tempo que se observam descontinuidades, também existem importantes continuidades, convivências e confluências.

Em certa medida, acreditamos que a identificação de divergências tão acentuadas pode ser atribuída à própria literatura da chamada Reforma Sanitária dos anos de 1980, que, na perspectiva de constituir uma memória e uma história que estabelecessem linhas de continuidade adequadas politicamente ao reformismo sanitário do referido período - nos termos de Teixeira e outros colaboradores, "recuperar o legado de uma época", que estaria "sendo interditado pelo regime autoritário" (Teixeira, 1988, s.p; ver também Braga e Paula, 1981; Luz, 1979) -, acabariam por exagerar ou absolutizar certos antagonismos. Como aponta Hochman, em sua análise do programa de governo de Kubitschek, candidato à presidência da República, a suposta polarização entre sanitarismo desenvolvimentista e sanitarismo campanhista, pelo menos até o fim dos anos de 1950, seria "artificial", além de "construída contemporaneamente por uma bibliografia que, oriunda do campo da saúde coletiva, o fez à luz da reforma sanitária brasileira dos anos 1980" (2009, p. 316).

Notadamente, a literatura que trata dos antecedentes da Reforma Sanitária dos anos de 1980 identifica no sanitarismo desenvolvimentista uma espécie de ponto de origem da referida reforma. Vê, ainda, que algumas de suas figuras-chave, entre as quais Mário Magalhães, Carlos Gentile de Mello e Samuel Pessoa, seriam, digamos assim, seus pais fundadores ou pioneiros, em uma genealogia histórica carregada de teleologia. Isso na medida em que visa a capturar seletivamente, nos processos e materiais da história, apenas os indícios, as evidências e os sentidos a priori mais adequados aos objetivos e às proposições da reforma dos anos de 1980, correndo o risco de menosprezar contextos e evidências que confeririam significados menos uniformes e artificiais, portanto mais plurais, a tal história ${ }^{3}$.

Sendo assim, será com base no pensamento sanitário do médico Mário Magalhães, observado aqui como um dos nomes mais representativos da corrente intelectual desenvolvimentista na saúde, em contraposição às formulações conceituais e às práticas do sanitarismo campanhista e do modelo do Sesp, que este texto se desenvolverá. Vamos nos valer, como fonte principal de análise, do livro organizado pelas pesquisadoras Silva e Morell (2008), que conta com a produção intelectual de Magalhães, arquivada com cuidado pela companheira
3. David Capistrano Costa Filho, por exemplo, importante figura da Reforma Sanitária, identifica Mário Magalhães, Samuel Pessoa e Carlos Gentile de Mello como intérpretes de um momento inaugural - os chama de "pioneiros" do "debate realmente sério da problemática da saúde” no Brasil, ignorando toda uma trajetória histórica anterior de sanitaristas que atuaram no país e que, bem ou mal, com todos os seus limites, restrições e possíveis equívocos, debateram e se envolveram seriamente com o tema (como a já bastante ampla historiografia atual sobre o assunto mostra). Cf. Costa Filho (1978, pp. 65-66). 
4. De acordo com Silva e Morell (2008, p. 11), só foi possível organizar o livro com os trabalhos de Mário Magalhães "graças ao dedicado empenho da Dra. Nise, sua companheira, que tratou de arquivar todos os textos de sua autoria”.

5. Mário trabalhou na Sudene, a convite de Celso Furtado, de 1959 a 1961, quando então o presidente Jânio Quadros determinou a volta de todos os cedidos para seus órgãos de origem. de tantos anos do sanitarista, a doutora Nise da Silveira, uma vez que, como veremos, Mário não gostava de assinar seus textos ${ }^{4}$.

\section{Mário Magalhães: cavaleiro andante da saúde pública}

Difícil não evocar a figura do Quixote: a paisagem é semelhante à da lendária Mancha, a figura é quase rigorosamente a do fidalgo enlouquecido pela sua robusta lucidez. [Mário] arrostou contra si todos os interesses da categoria que ele próprio pertenceu, a dos médicos, quando pregava, quase como Cavaleiro da Triste figura, que a saúde depende mais do desenvolvimento econômico que dos remédios, dos hospitais, da própria medicina [...]. Peregrinou incessantemente por todos os rincões do Brasil, meteu-se na África à época da Segunda Guerra Mundial, no trabalho gigantesco de barrar a invasão do território brasileiro pelos transmissores de malária e da febre amarela, em sua missão de Cavaleiro Andante da saúde pública. E ele mesmo era o Quixote e o Sancho, pois sua argúcia intelectual e sua visão teórica se alimentavam de seu entranhado senso de realidade, dos limites e dificuldades de um país subdesenvolvido (Oliveira, 1987, pp. 147-148).

Esse trecho do depoimento de Francisco de Oliveira, que foi aluno de Mário na Comissão Econômica para a América Latina (Cepal) e com ele conviveu e trabalhou na Superintendência de Desenvolvimento do Nordeste (Sudene), no tempo do economista Celso Furtado ${ }^{5}$, revela bem a figura um tanto especial que era o sanitarista. Desprendido de certas ambições, sobretudo das "glórias das letras impressas" (Idem, p. 147), ele era dono de uma "obstinada aversão à publicidade" (Silva e Morell, 2008, p. 10), a ponto de, inclusive, não assinar seus textos porque compreendia sua atividade no serviço público como uma obrigação e um compromisso que tinha com o povo brasileiro. Como lembra Celso Furtado (1987, p. 149), Mário não aceitava, “em nenhum momento, uma homenagem ou gesto qualquer de reconhecimento [...]. Por isso, ele não assinava nada. [Dizia que] não tinha importância quem assinava um papel. O que interessava era o que estava escrito". Descrito como rigoroso consigo mesmo, sem "nenhum traço de narcisismo" (Idem, p. 147 ), era tido como francamente sincero, frequentemente ácido e até muito duro, pois "dizia tudo aquilo que [...] achava e sentia"(Góes apud Escorel, 2000, p. 148), o que gerava situações às vezes desagradáveis, fazendo com que se envolvesse em muitas brigas e conflitos (Escorel, 2000, pp. 148 e 150-151).

Natural de Maceió, Alagoas, ingressou na Faculdade de Medicina de Salvador muito jovem, com possíveis 14 anos. Formou-se aos 20 anos e logo 
veio para o Rio de Janeiro, em 1925, onde cursou Higiene e Saúde Pública no então Instituto de Manguinhos. Rapidamente, ingressou no serviço público, na função de sanitarista do Departamento Nacional de Saúde do recém-criado Ministério da Educação e Saúde. Ali, ocupou muitos cargos, "desde o mais humilde, médico itinerante de Posto de Profilaxia Rural, até o de diretor de Departamento de Saúde Estadual” (Magalhães, apud Silva e Morell, 2008, p. 61). Passou a viver desde cedo com a também médica Nise da Silveira - que depois seria bastante reconhecida por seus trabalhos inovadores com pacientes psiquiátricos -, com quem se casou formalmente alguns anos depois. Sua casa, na rua Marquês de Abrantes, no Rio de Janeiro, que seu irmão Fausto Silveira definia como um "aparelho" e Francisco de Oliveira como "a casa da amizade", onde a "inteligência não colidia com a hospitalidade, o calor das discussões não dispensava a boa mesa e o bom vinho" (1987, p. 148), era frequentada por rodas de sanitaristas e até mesmo de autoridades:

[...] era um aparelho porque você podia chegar lá às dez da manhã e pedir almoço.

Dona Amélia preparava, você almoçava lá e ia embora. Aquilo funcionava de manhã até de noite... vinha alguém de São Paulo, ia pro aparelho, passava lá três dias e depois ia embora. Não tinha dia certo pros sanitaristas se encontrarem no aparelho. Tinha almoço e jantar e era frequentado por todo mundo... O Barros Barreto ia lá jantar com o Mário, os ministros da Saúde iam lá também. De um modo geral funcionava todas as noites. Se você chegasse lá às sete da noite sempre tinha novidade, sempre tinha uma conversa... era uma agitação! (Silveira apud Escorel, 2000, p. 80)

Mário deu aulas na Comissão Econômica para a América Latina (Cepal) sobre saúde, desenvolvimento e demografia; também no Instituto Superior de Estudos Brasileiros (Iseb) e na Escola Nacional de Saúde Pública (ENSP), criada em 1958, onde ministrava a disciplina "Fundamentos Socioeconômicos da Saúde”. Escreveu nos anos de 1950 e no começo da década seguinte para as revistas Desenvolvimento \& Conjuntura e Conjuntura Econômica, respectivamente da Confederação Nacional da Indústria e da Fundação Getúlio Vargas. Afastado de suas funções com o golpe civil-militar de 1964, sofreu perseguições e punições, tendo de responder a diversos inquéritos policiais militares (os famigerados IPMs), que acabaram não resultando em condenação alguma (Idem, p. 151). Com a saúde debilitada, acabou falecendo em 1986, vítima de um aneurisma na aorta abdominal, mas também de amargura e desânimo devido a certo ostracismo a que ficou relegado após o golpe de $1964^{6}$. Como disse certa vez a Francisco de Oliveira: "Viver é influenciar e eu não influencio nada mais" (Idem, p. 158).
6. Mário não foi cassado em 1964, mas transferido para o Serviço Nacional de Tuberculose (SNT), "para onde foram mandadas várias pessoas que tinham problemas ideológicos com o regime militar" (Escorel, 2000, p. 146). A intenção, de acordo com o depoimento de Germano Gerhardt (apud Escorel p. 147), era "isolá-lo", "deixá-lo fora de circulação”. Participou também como professor dos cursos da Associação Médica do Estado da Guanabara (Ameg), onde se reuniam diversos médicos críticos dos rumos da medicina no período da ditadura militar (Idem, pp. 148-149).

novembro 2015 


\section{Pensamento sanitário e sociabilidades intelectuais}

A literatura que busca compreender as diretrizes gerais do sanitarismo desenvolvimentista (Escorel, 2000; Braga e Paula, 1981; Teixeira, 1988), em grande parte, aponta um processo polarizado de ruptura dessa concepção com as orientações até então vigentes do chamado campanhismo. Quase se pode dizer, exagerando no antagonismo, que tudo o que se enuncia como característico da perspectiva desenvolvimentista na saúde se define pelo avesso ou em contraposição ao dito campanhismo. Sarah Escorel, por exemplo, importante estudiosa do tema, assim caracteriza esse embate:

Deu-se assim uma disputa de poder: de um lado os sespianos que se aliavam aos técnicos do Ministério da Saúde que defendiam o modelo de campanhas nacionais, verticais e não coordenadas entre si, e que garantiam para conjuntos de cargos técnicos e diretivos um pequeno feudo onde eram senhores. De outra parte aliavam-se os que queriam criar uma coordenação entre as campanhas e promover uma extensão de cobertura de saúde por meio de um modelo "nacional" de assistência que estivesse apropriado às nossas necessidades e à municipalização dos serviços de saúde. Essa proposta deixava no nível federal as ações de coordenação e controle, e passava para os municípios, mais próximos dos usuários, a atenção à saúde preventiva e curativa (Escorel, 2000, pp. 98-99).

Por sua vez, Braga e Paula sugerem que

[...] comparando os níveis de doença e as ações sanitárias dos "países pobres" aos dos "países ricos", concluíram [os sespianos e campanhistas] que para alcançar o mesmo nível de saúde bastava gastar os mesmos recursos e montar a mesma estrutura. A impossibilidade de tal procedimento não lhes era evidente [...] e por muitos anos perseguiu-se tal objetivo [...]. Observe-se que tal posição era defendida pelos norte-americanos, como se pode depreender da atuação da Sesp, patrocinada pela Fundação Rockefeller e que disseminou pelo Brasil, ao longo de quase 30 anos, unidades sanitárias-modelo, inadequadas à estrutura brasileira e às nossas possibilidades financeiras (Braga e Paula, 1981, p. 59).

O que se nota nessas duas citações é o reconhecimento de antagonismos inequívocos entre as concepções sanitaristas campanhista/sespiana e desenvolvimentista. Mas seriam tais concepções marcadas por antagonismos tão enfáticos assim, como sugere essa literatura, ou comportariam algum nível 
de interlocução e mediação? Para responder a isso, é importante iniciar esclarecendo o que de fato tem sido compreendido como característico de uma e outra concepção. No caso do campanhismo, o que geralmente se enfatiza é a presença de estruturas verticais de saúde, autônomas e independentes, sem maior integração, voltadas para o combate a doenças específicas. Tais estruturas viriam dos tempos da república oligárquica, nos anos de 1910 e 1920, mas ganhariam seu formato definitivo com as reformas de Barros Barreto de 1937 e 1941, no primeiro governo Vargas, que dariam origem aos serviços nacionais e às delegacias nacionais de saúde ${ }^{7}$, além de assumirem, nesse período, feições mais urbanas e, sobretudo, centralizadas e de âmbito nacional. Como salienta Faria:

[...] os estudiosos têm imputado à política varguista a verticalização das ações federais no campo da saúde pública. [...] O formato institucional preponderante teria buscado verticalizar as ações sanitárias, que seriam realizadas separadamente por doença. Assim, os serviços específicos seriam o modelo ou o padrão típico de organização sanitária, em virtude de uma concentração maior de gastos federais com os serviços de combate à lepra, à tuberculose, à malária. Dessa forma, os serviços nacionais de saúde, criados em 1941, teriam representado a consolidação de tendências verticalizantes (Faria, 2007, p. 62).

Esse modelo, apesar das intenções, não teria sofrido solução de continuidade com a implantação, em 1956, do Departamento Nacional de Endemias Rurais (DNERu) (Escorel, 2000; Fonseca, 2001)8.

Por sua vez, o chamado sanitarismo desenvolvimentista, assim batizado pela própria literatura do campo da saúde, evidentemente apresentou forte implicação com o projeto político-econômico mais amplo do país nos anos de 1950 e 1960, sendo tributário do que Bielschowsky (2009) identifica como "primeiro ciclo do desenvolvimentismo" brasileiro, cujo significado, apesar das controvérsias que o cercam, pode ser compreendido, grosso modo, a partir de certo "núcleo duro" com as seguintes características: 1) defesa de um projeto claro de industrialização; 2) intervenção e planejamento em prol do crescimento econômico;3) nacionalismo, de matiz variado, que incorpora desde uma "retórica ufanista conservadora" até "propostas de rompimento com o capital estrangeiro" (Fonseca, 2012, pp. 21-22).

No âmbito propriamente da saúde pública, tendo em vista a defesa que o sanitarismo desenvolvimentista faz do crescimento econômico-social como etapa prévia e necessária para a melhoria das condições de saúde, este se
7. A reforma de 1941, que consolida a estrutura do Departamento Nacional de Saúde (DNS), organiza os serviços nacionais em um total de dez (Lepra, Tuberculose, Febre Amarela, Malária, Peste, Doenças Mentais, Educação Sanitária, Fiscalização da Medicina, Câncer e Saúde dos Portos). Já as delegacias federais de saúde foram estabelecidas com a reforma de 1937 e depois redistribuídas pela de 1941, com o objetivo de "fortalecer a ação federal em determinadas localidades do país" (Fonseca, 2007, p. 219).

8. Segundo Cristina Fonseca, a criação do DNERu, pela Lei n. 2.743, de 6 de março de 1956 , "teve o propósito de unificar os esforços dispersos e, às vezes, redundantes que se faziam para controlar ou erradicar as doenças de massa, por meio de 'técnicas modernas de sanitarismo', dando-se maior rendimento às campanhas existentes e abrindo-se novas frentes com recursos mais substanciais" (2001, pp. 300302). A Divisão de Organização Sanitária (DOs) e os já citados serviços nacionais, dois ramos do antigo DNS (ambos estruturados nas reformas de 1937 e 1941) seriam os "principais esteios do DNERU". Seu primeiro diretor foi o sanitarista Mário Pinotti, identificado como "expressão dos programas verticais, em especial o de erradicação das doenças" (Hochman, 2009, p. 316). Segundo Escorel (2000, pp. 100-102), o DNERu não conseguiu atingir seu objetivo de propiciar maior integração e coordenação das estruturas de saúde pública, que permaneceram fragmentadas, dispersas e marcadas "por uma multiplicidade de ações superpostas", seja no âmbito do próprio DNERu, seja entre este e o Sesp. 
9. Faria (2007, p. 63) considera, por exemplo, que a "presença de serviços voltados para a profilaxia de doenças específicas, depois de 1930, não significou o fim dos centros de saúde, que ocuparam ainda importante lugar na organização dos serviços federais e estaduais, especialmente nas áreas interioranas". Ou seja, salienta a presença concomitante de estruturas mais horizontalizadas e integradas. caracterizaria por propor uma estrutura sanitária em boa medida inversa à campanhista: horizontalidade das ações, integração das estruturas de saúde e expectativas de descentralização ou de municipalização dos serviços. Ademais, o campanhismo é acusado de ser dispendioso, com exigência de elevada formação profissional e técnica, bem como de instalações caríssimas e sofisticadas, mas de baixa eficiência em geral, sobretudo em um país pobre de recursos como o Brasil, atravessado por carências e déficits de toda ordem - notadamente na saúde -, que o punham na escala dos países subdesenvolvidos. E o modelo do Sesp, instalado no Brasil em 1942, mas inspirado nas propostas mais antigas da Fundação Rockefeller, representaria o ápice dessa perspectiva, com suas estruturas copiadas dos países ricos, sobretudo dos Estados Unidos. Como salientava Magalhães, os sanitaristas brasileiros que iam estudar nesse país, patrocinados pela Fundação Rockefeller, voltavam "entusiasmadíssimos com a Saúde Pública Americana”, acreditando que bastava instalar no Brasil um "sistema de saúde igual que passaríamos a ter uma população tão rica, com tanta saúde como a americana” (Magalhães, em Silva e Morell, 2008, p. 82).

No entanto, apesar de a polarização ser inegável, é possível matizar de algum modo os seus níveis entre essas diferentes formulações. Com efeito, diversos estudos recentes, como os de Hochman (2009), Campos (2006), Paiva (2004), Mello (2010) e Faria (2007), têm procurado complexificar tais antagonismos, seja observando maior pluralidade e diferença nos referidos modelos $^{9}$ (entre cada um deles e entre sespianos e campanhistas, como veremos um pouco mais adiante), seja indicando não só uma razoável circulação entre atores filiados a uma ou outra orientação, como também convivências e admirações decorrentes de inscrições em redes de sociabilidades próprias aos circuitos de amizade e relacionamento no campo da saúde pública. Afinal, muitos dos sanitaristas desenvolvimentistas se formaram profissionalmente nas tradições de trabalho dos serviços nacionais, criados na era Vargas/Barros Barreto, como já foi dito, sendo com frequência funcionários de carreira subordinados às estruturas do Departamento Nacional de Saúde (DNS), órgão vinculado ao Ministério de Educação e Saúde (MES), "responsável pelo comando e pela execução dos programas na área da saúde" (Faria, 2007, p. 62), com relações de amizade e de militância na saúde pública muitas vezes em comum com seus supostos antagonistas, sespianos-campanhistas.

Samuel Pessoa, por exemplo, quadro do Partido Comunista Brasileiro (РСВ), sempre citado como um destacado sanitarista desenvolvimentista, foi bolsista da Fundação Rockefeller e diretor do Departamento de Saúde de São Paulo no Estado Novo. Dedica um dos seus mais importantes livros ao 
sanitarista Mário Pinotti, considerado, como já foi dito, um "ícone do modelo vertical e das campanhas de erradicação" (Hochman, 2009, p. 317) ${ }^{10}$. Mário Magalhães, por sua vez, trabalhou no Serviço de Profilaxia da Malária, ainda no tempo da Rockefeller, e no Serviço Nacional de Tuberculose, ocupando postos nas diretorias estaduais de saúde no período do Estado Novo. Não à toa, seu irmão, Fausto Silveira, lembra que, nos jantares e almoços que ocorriam com frequência em sua casa, Barros Barreto, figura-chave das reformas da saúde no primeiro governo Vargas - portanto, supostamente do chamado campanhismo -, era um personagem que se fazia presente, além de confidenciar que Magalhães teria escrito discursos para diversos ministros da pasta da saúde, inclusive para Mário Pinotti. Conta também como este último ficou "pavoneado" quando ele, Fausto Silveira e Magalhães foram à casa do sanitarista sugerir seu nome para o recém-criado Ministério da Saúde: "O Mário disse: 'Pinotti, chegamos à conclusão de que a única salvação pro Ministério é você assumir'. Ele ficou logo... pavoneado" (Magalhães apud Escorel, 2000, p. 96).

Cristina Fonseca, em seu belo estudo acerca da saúde no período Vargas, sugere, com base nos termos empregados pelo sanitarista Bichat de Almeida Rodrigues, que estes compunham uma "rede de gente que falava a mesma língua" (Fonseca, 2007, p. 197), ou seja, que reconheciam a importância de carreiras públicas de sanitaristas com tempo integral e dedicação exclusiva. Eles assumiam uma visão que os diferenciava dos médicos clínicos, além de se verem como técnicos com certa vocação missionária, encarregados de uma tarefa especial e civilizatória, não se tratando apenas de uma opção profissional, e sim de um modo de conduzir o poder público para "longe do asfalto e do ar-condicionado", rumo ao interior do país, nos termos do sanitarista Celso Arcoverde de Freitas (Fonseca, 2007, p. 173; Cunha, 2005, p. 111). Em depoimento a respeito do perfil profissional dessa geração de sanitaristas que "falavam a mesma língua", formados na "Era Barros Barreto", o mesmo Freitas esclarece:

[...] espírito público era a primeira coisa. Espírito público e resistência física [...]. E tinha que gostar das coisas do povo, apreciar tudo: a doença, a poesia popular - a poesia do povo é uma coisa deliciosa... Resistência física era para aguentar os embates das grandes viagens. Não se podia ser, como se diz no sertão, um sujeito lord, luxento. Tinha que se adaptar às condições de vida do povo do interior, enfrentar todas aquelas dificuldades. A outra condição era ter a grande faceta de idealista. Ela vai se criando com aprimoramentos, com os conhecimentos sobre a saúde pública e história da medicina que a pessoa ganha (Freitas apud Fonseca, 2007, p. 247).
10. Pinotti trabalhou por anos no Serviço Nacional de Malária e se tornou o primeiro diretor do DNERu, além de ministro da Saúde por duas vezes (no final do segundo governo Vargas e durante o governo Juscelino). 
Almir de Castro, sanitarista do Serviço Nacional de Peste, apresenta argumento semelhante: “[...] éramos uma geração entusiasmada com saúde pública, acreditávamos naquilo. Era gente que não se interessava por clínica. Mas, de um modo geral, esses nossos eram pessoas que toda a vida trabalharam em tempo integral" (Idem, p. 246).

O próprio Mário Magalhães, na conferência "Políticas de Saúde Pública desenvolvidas nos últimos 50 anos no Brasil”, pronunciada na Câmara dos Deputados em 1979, se identifica com o grupo que o acompanhava nas proposições do sanitarismo desenvolvimentista como técnicos a serviço da saúde, ou seja, como sujeitos não propriamente "políticos", mas dotados daquilo que Freitas identificou em seu depoimento como "idealismo" e "espírito público". Por isso, logo a seguir, Magalhães (apud Silva e Morell, 2008, p. 90) conclui: "sempre fomos interessados pela nossa profissão". Na mesma palestra, ao se referir criticamente aos médicos da Saúde Pública que iam para os Estados Unidos e "ficavam como sátrapas, forçando a execução de um regulamento sanitário que não se adaptava, de maneira nenhuma, às necessidades do Brasil”, afirmava que ele teria sido um destes, pois como diretor de Saúde Pública do Sergipe foi "preparado para acreditar no sistema" e "acreditava", trabalhando "para que isso acontecesse" (Idem, p. 84). Em comunicação na III Conferência Nacional de Saúde, em 1963, contexto muito acirrado de polarização política, reconhece que os anos de 1937 a 1945 foram o momento "áureo do movimento sanitário no Brasil" (Idem, p. 140). E acrescenta: "Nesse período, a ação sanitária do governo da União, chefiada pelo ilustre professor Barros Barreto, estendeu-se por todo o território nacional e a tese da salvação nacional pelo trabalho da saúde pública dominou a todos, criando-se uma verdadeira mística" (Idem, p. 140, grifo meu).

A historiadora Angela de Castro Gomes (1999), ao analisar certos grupos de intelectuais-escritores cariocas atuantes nos anos de 1930, se vale da formulação de lugares (ou espaços) de sociabilidade, proposta por alguns estudiosos franceses, que a definem em uma dupla dimensão: 1) a de rede que se constitui nos ambientes institucionais, formais ou não, e que promove aprendizados e trocas de experiência e faz circular e fermentar ideias; 2) a que envolve um clima mais propriamente afetivo, de amizade, pessoal ou profissional. E então conclui:

[...] se os espaços de sociabilidade são "geográficos", são também "afetivos", neles se podendo e devendo captar não só os vínculos de amizade/cumplicidade e de competição/hostilidade, como igualmente a marca de uma certa sensibilidade produzida 
e cimentada por eventos, personalidades e grupos especiais. Trata-se de pensar em uma espécie de "ecossistema", onde amores, ódios, projetos, ideais e ilusões se chocam, fazendo parte da organização da vida relacional (Idem, p. 20).

Por tudo o que foi dito até aqui, parece que, ao menos durante um importante período, os sanitaristas - fossem eles campanhistas ou crescentemente desenvolvimentistas (Mário Magalhães inclusive) -, mesmo que com diferenças, "competições e hostilidades", falavam uma "língua comum". Compartilhavam ainda, vale dizer, certos espaços de sociabilidade, estabelecendo laços de amizade pessoal e profissional, vendo-se como sanitaristas idealistas que adentravam pelo interior, para "longe do asfalto e do ar-condicionado", com uma "sensibilidade produzida" em experiências comuns de trabalho. Sendo assim, comungavam de expectativas muito próximas em termos da adesão a certos ideais de realização no campo da saúde pública, e isso nem se refere a estratégias e visões políticas e institucionais (nas quais residem certas diferenças que se acentuarão nos anos de 1950 e 1960), e sim aos valores e aos sentidos da ação profissional, uma "mística" da "salvação nacional pelo trabalho da saúde pública”, o que talvez explique os vínculos e laços de Magalhães e Samuel Pessoa, por exemplo, com sanitaristas como Mário Pinotti, que defendia concepções em boa medida divergentes das que eles vinham crescentemente adotando. De acordo com Gilberto Hochman, essa era uma

[...] geração que intervinha, contribuindo para a construção do aparato institucional [da saúde] definindo prioridades e acumulando experiências no trabalho cotidiano pelo interior do país, atuando não só como formuladores de propostas políticas para o setor, mas também como implementadores de políticas. Portanto, é muito difícil separar o processo de institucionalização da saúde pública, que se desenvolve a partir dos anos 1930, da trajetória pessoal e profissional dessa geração que se constitui ao longo desse processo. Parte dessa geração de médicos-sanitaristas ocuparia os principaispostos do Ministério da Educação e Saúde e, depois de 1953, do Ministério da Saúde (Hochman, 2001, p. 143, grifo meu).

De modo idêntico, Fonseca assinala que essa seria uma geração formada profissionalmente "nos diferentes serviços que compunham o Mesp [Ministério da Educação e Saúde Pública], em particular no Departamento Nacional de Saúde (DNs) e no Serviço Especial de Saúde Pública (Sesp), as principais instituições da área de saúde pública integrantes do ministério nas décadas de 1930, 1940 e 1950" (Fonseca, 2007, p. 173). 
11. O Iaia foi instituído para administrar os programas de saúde do hemisfério ocidental e estava subordinado ao Escritório para a Coordenação das Relações Culturais e Comerciais entre as Repúblicas Americanas, criado pelo governo dos Estados Unidos em 1940. O Sesp resultou de um convênio envolvendo o governo brasileiro e o Iaia, que, por sua vez, era o principal responsável pelo financiamento das ações do Sesp (95\%) no início (1942-1943), mas aos poucos foi minguando sua participação, até se tornar inexpressiva em 1959 (Campos, 2000, pp. 200-210).
Modelos e redes: para além das divergências, algumas coexistências

Estudos recentes, como os já mencionados de Campos (2006), Mello (2010) e Faria (2007), têm salientado também que, em termos de modelos de saúde, as diferenças não eram tão marcadas assim. Primeiramente, é preciso dizer que entre campanhistas e sespianos as identidades não eram exatamente como certa literatura apresenta (Escorel, 2000; Braga e Paula, 1981). Com efeito, de acordo com Campos (2006), que desenvolveu minucioso trabalho sobre a atuação do Sesp, um dos principais adversários das concepções campanhistas eram os próprios sespianos, que advogavam muito mais por uma ação sanitária horizontal, atravessada por uma rede de centros e postos de saúde de base local e permanente subordinados, ao menos em tese, aos departamentos estaduais (os quais, em geral, não conseguiam sustentar financeiramente essas redes de saúde e, por isso, elas continuavam muitas vezes vinculadas ao Sesp). Nesse caso, eram muito diferente das estratégias verticais de agências autônomas, hierarquicamente subordinadas à estrutura federal (os serviços nacionais do DNS ou, a partir de 1958, o DNERu), portanto de viés centralizador, encarregadas de campanhas de combate a doenças específicas. Segundo Campos, os norte-americanos não concordavam com tal estrutura vertical e centralizada que, de acordo com Eugene Campbell, o representante do Instituto de Assuntos Interamericanos (Iaia) ${ }^{11}$ no Brasil, era "dispendiosa e ineficiente", sem "nenhuma colaboração entre si e sem vinculação com os departamentos estaduais de saúde", e indicavam ao governo brasileiro a opção pelo modelo dos centros de saúde (Campos, 2006, p. 260). Henrique Maia Penido, superintendente do Sesp em 1958, de modo idêntico, considerava, dez anos depois, que um dos motivos que travava o desenvolvimento da rede horizontal integrada no Brasil era o modelo dos serviços verticais, "dispendios[o] e ineficiente", mas que o governo insistia em manter, fazendo uma crítica ao recém-criado DNERU, expressão maior, naquele momento, do modelo centralizador e vertical (Idem, s.p).

Segundo Campos, embora houvesse uma competição entre esses dois modelos pelo menos desde 1948, verificava-se a coexistência de ambos na administração sanitária brasileira, com o campanhismo atuando preferencialmente nas áreas rurais e o Sesp nas áreas urbanas, em articulação com os departamentos de saúde estaduais e municipais (Campos, 2000, pp. 214-215). Tal coexistência, aliás, pode ser notada nas estruturas do próprio Departamento Nacional de Saúde (DNS) do governo federal, que incorporava, por iniciativa de Barros Barreto (Campos, 2006, p. 257; Mello, 2010; Faria, 2007) - diretor deste órgão 
de 1935 a 1945 -, o modelo de rede horizontal e permanente de unidades de saúde, ou horizontal integrado, ou ainda distrital, que o Sesp buscava expandir a partir de 1948, ainda que subordinado, pode-se dizer, à direção hegemônica do modelo vertical campanhista, centralizador e normativo. Conforme aponta Faria, foi na "década de 1920, notadamente em São Paulo, que surgiu a proposta de criação de centros de saúde. Entretanto, foi no governo de Getúlio Vargas que houve um significativo aumento desse tipo de serviço no pais. A partir de 1937 institui-se, nos serviços sanitários de vários estados, o sistema distrital dos centros de saúde e postos de higiene em substituição às inspetorias especializadas" (Faria, 2007, p. 62, grifo meu).

Com efeito, Barros Barreto - que, graças à sua posição de diretor do DNS e principal formulador das reformas de 1937 e 1941, geralmente é apresentado como o representante-mor das propostas verticais/campanhistas ${ }^{12}$ - considerava o centro de saúde "a unidade polivalente que, servindo a uma área determinada", realizaria o "controle das doenças transmissíveis", além da "proteção médico-sanitária da gestante e da criança, o saneamento e a polícia sanitária das habitações e logradouros, a higiene do trabalho e da alimentação, e os exames periódicos de saúde" (Barreto apud Campos, 2006, p. 257). Nesse sentido, conclui Campos:

[...] como resultado das reformas da administração Capanema e da ação do Sesp, elementos dos dois modelos de administração sanitária coexistiam na administração de saúde pública: o modelo vertical, representado pelos Serviços Nacionais; e o modelo horizontal, formado por uma rede de unidades de saúde - centros e postos. O Sesp contribui para expandir este segundo modelo, com sua política de levar saúde pública básica aos estados subdesenvolvidos do país, assinando convênios para modernizar, racionalizar e padronizar a administração sanitária estadual [...]. Ambos os modelos, portanto - o vertical e o horizontal permanente -, são complementares neste processo, no sentido em que contribuem para a institucionalização da saúde pública e a expansão da autoridade do Estado no Brasil (Idem, p. 259).

Assim, pode-se dizer que, embora o sanitarismo desenvolvimentista se opusesse ao Sesp, seus modelos de administração em boa medida se aproximavam. Ambos defendiam uma estrutura mais horizontal e integrada de serviços de saúde - a municipalização pleiteada por Magalhães e seu grupo, que, de certo modo, se identificava, apesar de algumas diferenças, com o modelo distrital sespiano - e eram divergentes ao campanhismo (Campos, 2006, p. 265). Tal oposição parece decorrer muito mais pelo fato de o sanitarismo desenvolvimen-
12. Faria (2007, p. 62) discorda dessa avaliação mais corrente, identificando Barros Barreto como um dos "principais incentivadores" do modelo de centros de saúde (programas horizontais). 
13. Eduardo Kertész narra o curioso episódio na apresentação do livro de Silva e Morell (2008, pp. 21-22), explicando como o "médico de caserna", Aramis Athayde, ministro da Saúde em abril de 1963, veio a se tornar o "veiculador oficial de importantes teses elaboradas pelo Dr. Mário Magalhães". tista identificar no Sesp uma orientação: 1) não adequada à realidade brasileira, porquanto importada dos Estados Unidos e alinhada com os organismos internacionais; 2) que via a saúde como uma questão muito mais técnica que econômico-social; 3) em termos financeiros, de alto custo e pouco eficiente. Magalhães se refere em um texto apresentado na III Conferência Nacional de Saúde, de 1963, da seguinte maneira:

Desde que iniciou suas atividades, o Sesp passou a colaborar com os estados, instalando serviços locais de saúde com a intenção manifesta de entregá-lo às autoridades locais ou às administrações estaduais tão logo funcionassem normalmente. Até hoje, decorridos vinte anos, poucos desses serviços puderam ser devolvidos. Essa devolução foi difícil até agora, pois os custos de operação eram incompatíveis com a situação econômico-financeira dos estados e municípios. De acordo com relatório da Fundação Serviços de Saúde Pública (FSESP) sobre o ano de 1961, a entidade administrava, em treze estados, 259 unidades sanitárias (206 postos e 53 subpostos) e dava assistência financeira a 89 outros (oitenta postos e nove subpostos) em outros sete estados. É por todos esses motivos que parece indispensável procurar novas estruturas para a organização da saúde pública nacional (Silvia e Morell, 2008, pp. 140-141).

É possível que a caracterização de uma administração sanitária atravessada por diferenças tão marcantes se deva aos próprios atores do sanitarismo desenvolvimentista, que as compreendiam dessa forma. Com efeito, se acompanharmos o discurso do então ministro da Saúde Aramis Ataíde, pronunciado em 1955 e provavelmente escrito por Mário Magalhães - ou ao menos expressando claramente suas teses ${ }^{13}$-, vemos que tal polarização se revela. Tratando dos "problemas da organização sanitária”, assim se expressa o ministro:

Nesse ponto precisamos confessar que a partir do momento em que os órgãos da administração federal de saúde tomaram maior incremento, sob a direção do eminente professor Carlos Chagas, não há dúvida de que se foi acentuando uma tendência para a centralização. Tal tendência criou uma doutrina que, gradativamente, passou a ter o apoio da grande maioria dos técnicos de saúde no Brasil. O ponto principal era que as medidas sanitárias deveriam ser impostas e, para que sua ação fosse rápida e enérgica, a autoridade de seus executores devia provir de escalão mais alto que o município. Além do mais, achavam que nossas comunas não dispunham de recursos suficientes para abordar os difíceis problemas locais de saúde. Esta doutrina terminou inteiramente vitoriosa na administração do Dr. João de Barros Barreto, a quem, prazerosamente, rendo minhas homenagens pelos extraordinários serviços que prestou ao Brasil, 
porquanto, incontestavelmente, foi ele quem deu amplitude nacional ao movimento sanitarista. A administração sanitária ficou, assim, centralizada no Governo Federal e nos governos estaduais (Ataíde, apud Silva e Morell, 2008, p. 39).

Ou seja, para além do elogio ao sanitarista Barros Barreto, há na fala de Aramis Ataíde uma crítica à centralização e a uma concepção imposta de cima, o que sugere a defesa de uma proposta de organização da saúde pública, por parte do próprio ministério, desconectada com a forma até então vigente, notadamente expressa no modelo vertical/centralizador, mas que, como vimos, embora fossse dominante, não era a única existente.

Em alguma medida, pode-se dizer que tal processo refletia as tensóes ideológicas próprias do período conturbado da Guerra Fria e seus efeitos no Brasil (Campos, 2006, p. 265). Magalhães chega a afirmar que, desde o governo Dutra, seus adversários acusavam de comunistas quem dizia que a "saúde pública não era assunto de médicos, mas de desenvolvimento": "Não era fácil essa designação, no tempo do Dutra! Apesar de ter sido um governo legal, foi muito reacionário" (Magalhães, apud Silva e Morell, 2008, p. 86). No entanto, parece ter sido dos anos de 1960 em diante, mais precisamente no período do governo João Goulart, que certos antagonismos se acentuaram. Com efeito, em uma conferência pronunciada em 1962, em Genebra, nas Nações Unidas, Magalhães acusa os economistas dos países ocidentais, notadamente dos Estados Unidos, e seus “epígonos nos países subdesenvolvidos" de afirmarem a "incompatibilidade entre desenvolvimento econômico e crescimento demográfico", criando a "necessidade de que nós, dos países subdesenvolvidos, recebamos com suspeitas e espírito crítico os programas de reformas sociais originadas nessas países para serem aplicados nos nossos" (Idem, p. 108). Opunha-se, pois, sobretudo ao que considerava uma visão importada, trazida de fora por organismos internacionais e por "técnicos nacionais que, pela sua formação 'científica' ocidental não se libertaram das ideias que lhes foram impostas" (Idem, ibidem). Critica o Fundo Monetário Internacional (FMI), cujas teorias "podem ser excelentes para os países desenvolvidos, mas que não servem” para os países da América Latina (Idem, p. 109). Adverte que a "experiência brasileira" vem demonstrando que, "na programação das atividades sanitárias, a palavra final deve ser reservada a técnicos brasileiros" (Idem, p. 104). E em outro texto afirma: "O grande perigo e o que prejudicou muito o desenvolvimento sanitário dos países da América do Sul, e consequentemente seu desenvolvimento econômico, foi a interferência nefasta das organizações internacionais, que sempre propu- 
14. Segundo o sanitarista, embora no relatório o Sesp finalmente reconheça seus equívocos, na prática não reformula nada $\mathrm{da}$ sua programação: "o mais grave, porém, é que os dados publicados pelo referido serviço revelam que o programa continua sendo o mesmo e consequentemente sem apresentar o mínimo resultado" (Magalhães, apud Silva e Morell, 2008, p. 126).

15. Em outro comentário a esse relatório, cita um artigo da revista Desenvolvimento \& Conjuntura, provavelmente escrito por ele mesmo, que era colaborador da revista, como prova de que, seram planos e programas para que esses países gastassem inutilmente seus recursos" (Idem, p. 92).

O Sesp era, nesse caso, o exemplo acabado de uma programação inadequada, estrangeira, exclusivamente técnica, e de uma saúde pública custosa, pouco eficiente, porque deslocada da realidade cultural e econômica do Brasil: "organização caríssima, tipicamente americana, praticamente sem nenhum benefício para o Brasil”, nas palavras de Magalhães (Idem, p. 87). Analisando as três atribuições da instituição definidas na sua fundação - (1) saneamento do vale do Amazonas e assistência médico-sanitária dos trabalhos ligados ao desenvolvimento da região; (2) preparo de profissionais em geral para trabalhos em saúde pública; (3) colaboração com o Serviço Nacional de Lepra -, considera que apenas a formação de profissionais obteve algum resultado, isso porque, salienta ironicamente, "não faltam candidatos a viagem de estudos ao estrangeiro" (Idem, p. 123). O fracasso dos outros objetivos é que teria levado o Sesp, para justificar sua existência, a se enveredar nas "atividades gerais de saúde pública, passando a instalar serviços em numerosos munícipios dos estados de várias regióes do Brasil” (Idem, ibidem).

No entanto, segundo Mário, apesar dos vultosos recursos destinados às ações do Sesp, os serviços médico-sanitários prestados mantiveram-se os mesmos e a "percentagem de óbitos de causas mal definidas e desconhecidas nas áreas mínimas trabalhadas" pela instituição praticamente não se alterou, apresentando resultados que em quase nada beneficiaram "as populações a que pretend[iam] servir" (Idem, p. 133). Isso tudo apesar das condições de autonomia administrativa e financeira de que a instituição gozava, com liberdade para "admitir o pessoal necessário, pagando salários que considera[sse] adequado", ou seja, sem as "restrições orçamentárias que os órgãos integrantes do Ministério da Saúde" tinham, com salários limitados e chefes escolhidos por "injunções políticas e não técnicas" (Idem, pp. 122-123). Aliás, esta nos parece ser uma importante fonte de atrito e de indisposição em relação ao Sesp: o poder e a autonomia da instituição, com orçamentos elevados, às vezes até maiores do que os do Ministério da Saúde, como disse certa vez um superintendente do órgão (Campos, 2006, p. 265).

\section{Salvação nacional pela saúde pública ou pelo desenvolvimento?}

Mário Magalhães gostava muito de se referir a um relatório de 1956 do Sesp, em que os dirigentes finalmente fazem uma espécie de "confissão de erros" dos programas da instituição. Isso depois de catorze anos no Brasil, o que sugere 
como certas divergências, na verdade, precedem o período conturbado dos anos de 1960, embora nos pareça correto dizer que tenham se acirrado nesse período. O trecho é longo, mas elucidativo:

De um lado, os técnicos do Sesp vêm sentindo a necessidade de uma revisão dos métodos de trabalho usados em nossas unidades sanitárias, que certamente podem e devem ser aperfeiçoadas, para que o Serviço possa manter um caráter dinâmico e pioneiro de saúde pública brasileira. Os motivos de nossa deficiência são vários, sobressaindo-se entre eles, porém, a tentativa que fizemos de aplicar, em nossas áreas, esquemas do trabalho calcados nos outros países, sem levar em conta as profundas diferenças econômico-sociais existentes entre estes países de economia predominantemente agropastoril e os de nível industrial e tecnológico avançado. À primeira vista poderá parecer, assim, que todo trabalho já realizado tenha sido improfícuo. Tal, entretanto, não se dá, pois a experiência obtida numa época em que quase nada se sabia de muito nos servirá para a escolha do método mais condizente com nossas condições culturais. Os problemas que nos afligem são os encontrados nos países chamados subdesenvolvidos, de economia fraca, com altos coeficientes de mortalidade geral e infantil, decorrentes do baixo padrão de vida do povo. Por este motivo devemos limitar os recursos disponíveis à resolução de problemas imediatos, sem deixar de reconhecer, entretanto, que essa resolução, no momento, depende menos dos serviços de saúde pública do que de outras instituições governamentais, que devem promover o aumento da riqueza, isto é, o aumento da produção de bens para que o processo de aculturação não se torne estéril (Magalhães, apud Silva e Morell, 2008, p. 142).

Esse relatório, a nosso ver, é emblemático das posições críticas de Magalhães ao Sesp e talvez por isso ele o repita tanto ${ }^{14}$. Isso por duas razões básicas. Primeiro porque serve para o sanitarista mostrar que o pouco que o relatório reconhece de validade na ação do Sesp, consequência de um tempo em que "quase nada se sabia", servindo ao menos "para a escolha de método mais condizente com as condições culturais" do Brasil, já era sabido, segundo Magalhães, por um grupo de sanitaristas brasileiros desde $1946^{15}$. O próprio presidente Vargas teria, em sua mensagem ao Congresso em $1951^{16}$, apontado tal direção, ao afirmar que o problema vinha sendo tratado de modo invertido, atribuindo-se ao baixo nível de saúde do brasileiro as razões de sua pobreza quando "na verdade o povo é doente porque ainda não possui os meios para comprar a sua saúde, sob a forma de alimentação adequada, ambiente higiênico e sadio regime de trabalho (Idem, p. 113) ${ }^{17}$. desde pelo menos o ano de 1948 (nesse caso, não 1946), "tudo era sabido" (Idem, ibidem).

16. É interessante observar como o discurso de Vargas ecoa as ideias de Mário Magalhāes e do sanitarismo desenvolvimentista. É possível observar isso pela semelhança absoluta entre os ideais dos sanitaristas desenvolvimentistas e as propostas contidas na fala de Vargas. Seu irmão, em depoimento registrado por Sarah Escorel, afirma que Mário teria escrito o discurso de vários presidentes, como Juscelino e João Goulart, e de diversos ministros da Saúde, como Mário Pinotti e Aramis Athayde (Escorel, 2005, pp. 96-97), podendo-se incluir talvez o do ministro Estácio Souto Maior (Silva e Morell, 2008, p. 357) e supostamente até o do primeiro-ministro Tancredo Neves (Idem, p. 90).

17. Mário Magalhães, tal como nesse discurso de Getúlio Vargas (quem sabe escrito pelo próprio Mário), muitas vezes empregava o termo ambíguo "comprar saúde", referindo-se à possibilidade de as populaçōes dos países desenvolvidos poderem usufruir de situações favoráveis de bem-estar - portanto, seria possível "comprar saúde", ou seja, ter acesso a condiçōes de vida saudáveis (moradia, emprego, renda, lazer, boa alimentação etc.). Não fica, porém, completamente claro qual o entendimento desse "comprar saúde" - se isso se referia apenas a essa capacidade do Estado de prover saúde em sentido amplo, dado seu desenvolvimento econômico, ou se também indicaria a possibilidade de os cidadãos terem acesso à assistência privada, tendo em vista sua condição de renda elevada. Como Mário gostava de dizer, a saúde é um "bem que se compra” (Idem, p. 107); "o povo deve ter meios para pagar por serviços médicos de alta qualidade[...]" (Idem, p. 103). 
18. Segundo Escorel, Mário Magalhães considerou a ideia do círculo vicioso da pobreza e da doença importante e consequente porque "chamava a atenção para a saúde como decorrência da economia" (Escorel, 2000, p. 78). De modo semelhante, David Capistrano Costa Filho afirma que apenas por estabelecer "liames entre economia e saúde" se explicaria a boa recepção que uma tal ideia "falsa" obteve dos "pioneiros" do "debate realmente sério da problemática da saúde, como Mário Magalhães da Silveira, Samuel Pessoa e Carlos Gentile de Mello" (Costa Filho, 1978, pp. 65-66).
A segunda razão, a nosso ver, central na "confissão de erro" dos técnicos do Sesp, trata do reconhecimento de que a solução dos problemas de saúde no Brasil "depende menos dos serviços de saúde pública do que de outras instituições governamentais, que devem promover o aumento da riqueza, isto é, o aumento da produção de bens para que o processo de aculturação não se torne estéril", como indica o referido relatório, tese claramente identificada com as posições de Magalhães e de seu grupo. Com efeito, uma das questões-chave das posições críticas do sanitarismo desenvolvimentista refere-se, como dissemos na introdução, às estratégias de ação alicerçadas no que se torna uma espécie de ideia-força do período, ou seja, o círculo vicioso da pobreza e da doença: a pobreza produzindo doença e a doença produzindo mais pobreza, em um processo de retroalimentação e amplitude descendente ou crescente, consolidando a perspectiva de que a saída para isto - a possibilidade de superação do quadro crítico da saúde pública - só se efetivaria por intermédio de uma aposta decidida no desenvolvimento e progresso econômico. Com certeza, essa era uma questão nuclear, pois de um modo geral a inquietação dos sanitaristas desenvolvimentistas devia-se à visão que consideravam invertida desse processo por parte de sespianos e campanhistas, com consequências negativas no avanço da saúde pública.

Com efeito, Magalhães era um convicto de que a pobreza é que devia ser prioritariamente confrontada, vale dizer, as condições de atraso e subdesenvolvimento do país, de forma a proporcionar progresso econômico e social e, consequentemente, saúde ${ }^{18}$. Citando a si mesmo em um texto publicado na revista Desenvolvimento \& Conjuntura em 1961 afirmava:

\footnotetext{
O ponto fundamental da tese que defendo é que a saúde do homem, no seu conjunto, é um problema de superestrutura. Assim, pois, o planejamento de sua organização deve basear-se na estrutura econômica da Nação. A medicina preventiva e a técnica de saúde pública apressam a obtenção de resultados favoráveis, propondo o que de melhor é possível fazer, em dado momento, para vencer rapidamente etapas de desenvolvimento sanitário, não podem porém se sobrepor às condições econômicas e sociais dominantes (Magalhães, apud Silva e Morell, 2008, p. 112).
}

Tratando da questão do combate à tuberculose, em um texto de 1946, ele acentuava que o declínio da mortalidade por essa enfermidade decorreria de uma série de fatores sociais, como a melhora do salário dos trabalhadores, das condições de trabalho, da situação habitacional e da alimentação, opondo-se, por esse motivo, à Campanha Nacional contra a Tuberculose, apresentada 
pelo diretor geral do Serviço Nacional de Tuberculose (SNT), que propunha um "aumento substancial de leitos para isolamento dos doentes" de forma a "evitar o contágio". Considerava isso um equívoco por não levar em conta a limitação da renda nacional, o grande número de doentes e a carência absoluta de técnicos, "consequência do atraso econômico do país", e esclarece: "Mas supondo que fosse possível construir, equipar e fazer funcionar um número suficiente de leitos para isolar um percentual razoável de doentes, essa providência, mesmo acompanhada de outras medidas médico-sanitárias, resolveria o problema da tuberculose? Não, é o que respondem muitos estudiosos do assunto" (Idem, p. 51).

E mais à frente conclui:

Resulta assim evidente, em que pese a opinião dos infeccionistas, que da mesma forma que a semente só germina quando encontra terreno adequado e satisfatórias as condições de temperatura, umidade, insolação, o bacilo da tuberculose só chega a desenvolver a doença quando se instala em organismo que, por sua situação geral, ofereça condições favoráveis. O grande número de pessoas que nas grandes cidades apresenta evidências de infecção nas quais esta não evolui até a doença não permite outra conclusão. Tudo isto não significa que não me aliste com grande entusiasmo entre os que opinam que se deve providenciar o aumento de leitos para tuberculosos, bem como o desenvolvimento dos demais armamentos na luta contra a tuberculose, à frente já se vê, os dispensários. Isto, porém, como uma simples providência de rotina de assistência social, pois sendo a tuberculose um problema social, ao Estado compete amparar os doentes, dentro de suas possibilidades orçamentárias, nunca porém dando a estas providências as honras de uma campanha que se destinaria, em última análise, à erradicação da tuberculose (Idem, p. 55).

Em conferência nas Nações Unidas, em 1962, tratando dos "Problemas sanitários dos povos subdesenvolvidos”, reafirma suas convicções:

Os problemas que nos afligem são aqueles mesmos encontrados nos chamados países subdesenvolvidos, onde a economia é fraca e os índices de mortalidade geral e infantil são altos devido ao baixo nível de vida do povo. Por essa razão, devíamos limitar os recursos disponíveis para a solução de problemas imediatos, lembrando, porém, que no momento tais soluções dependem menos dos serviços de Saúde Pública do que de outras instituições governamentais. Estas últimas deveriam promover um aumento da riqueza, isto é, um aumento da produção de bens, se não se deseja tornar estéril o processo de aculturação. Na sua melhor concepção, portanto, um programa de 
19. Por isso esse período foi identificado como de "otimismo terapêutico".
20. Isso mostra como a própria perspectiva de defesa da "saúde pública como salvação nacional", nos termos mais plenamente campanhistas, também vinha sofrendo rearranjos e redefiniçōes, não se podendo indicar, sobretudo nos anos de $1950 \mathrm{em}$ diante, de forma alguma uma mera continuidade das políticas sanitárias dos anos do primeiro governo Vargas. Note-se, ademais, que Magalhães, em diferentes momentos (tanto no relatório geral do xv Congresso Brasileiro de Higiene em 1962 quanto na sua exposição no I Simpósio sobre Política Nacional de Saúde na Câmara Federal em 1979) manifestava esperança com a chegada de Juscelino ao poder, o "idealizador do binômio energia e transporte", vendo-o como um aliado na defesa do desenvolvimento econômico em sua relação com a saúde (Magalhães, apud Silva e Morell, 2008, pp. 73 e 88). saúde pública para países subdesenvolvidos deveria ser integrado num plano geral de desenvolvimento econômico até onde o permita a renda nacional (Idem, p. 105).

Tal questão me parece ser o ponto central da crescente diferenciação e polarização, sobretudo dos anos de $1950 \mathrm{em}$ diante, se acentuando nos anos de 1960, entre sanitaristas desenvolvimentistas e adeptos do sanitarismo mais propriamente campanhista, em um processo de deslocamento que vai de uma visão notadamente defensora do desenvolvimento econômico e da distribuição da riqueza como precondição para a melhora da saúde da população brasileira, aos que reconheciam a importância do progresso e do desenvolvimento, mas entendiam que, dadas as condições de avanço das novas terapêuticas e da profilaxia no combate às enfermidades (inseticidas, sulfas, antibióticos etc.) produzidas no pós-Guerra - as ditas “novas armas sanitárias” (Hochman, 2009, p. $324)^{19}$-, era possível reduzir ou até eliminar certas doenças a custos razoáveis, independentemente do desenvolvimento econômico, por isso identificada, de acordo com Hochman, como “'concepção estrita' das relações entre saúde e desenvolvimento" (Idem, p. 322). Como salientou Juscelino Kubitschek, em sua primeira mensagem ao Congresso Nacional como presidente da República: "Para muitas destas enfermidades que mais afligem as populações dos países subdesenvolvidos, novas descobertas da terapêutica e da profilaxia têm tornado o seu combate, e consequentemente sua grande redução, ou mesmo eliminação, independente dos problemas de desenvolvimento econômico e de aparelhamento médico-sanitário de custo elevado" (Kubitschek apud Hochman, 2009, p. 327).

Esse discurso, em grande medida antissanitarista/desenvolvimentista, portanto em oposição aos argumentos de Magalhães e seu grupo (mas também antissespiano, quando sugere prescindir "de aparelhamento médico-sanitário de custo elevado" ${ }^{20}$, ecoava a "nova era" anunciada pelo médico Mário Pinotti na abertura do x Congresso Brasileiro de Higiene, em Belo Horizonte, em 1953, com a presença de Kubitschek, governador de Minas Gerais à época. Com efeito, em sua fala Pinotti salientava o momento oportuno, devido aos avanços da medicina alcançados na Segunda Guerra Mundial, para "cruzadas nacionais", ou seja, para ações de feitio campanhista contra as "doenças endêmicas e epidêmicas que assolavam o Brasil ao tempo de Miguel Pereira" (Idem, p. 321).

Apesar disso, a nosso ver, tanto em um caso como no outro, as posições contrastantes não desconheciam a necessidade de incorporar algo da visão oposta: a necessidade e a importância do desenvolvimento, para os adeptos 
das orientações mais campanhistas, e o reconhecimento das conquistas da ciência e da medicina nos avanços e bons resultados na saúde, por parte dos desenvolvimentistas. Nesse caso, o próprio Magalhães reconhece que seria "discussão ociosa" buscar saber se a melhora da saúde resultaria "de uma ação direta de medidas sanitárias ou do desenvolvimento nacional que se processou durante o período. Os fatos se intercalam e se interdependem [...]" (Magalhães, apud Silva e Morell, 2008, p. 115). Em um texto de 1961 sobre "Programação de Saúde Pública”, acrescenta:

Aí está, para citar alguns fatos que marcam a história do país, a luta contra a febre amarela em 1903, e depois em 1928, e finalmente a erradicação do estegomia, a erradicação dos Anopheles gambial, do Nordeste, 1938-1942; o controle da malária em todo o país a partir de 1948; a campanha de iodetação do sal para erradicação do bócio endêmico; a campanha contra a bouba, com resultados muitos satisfatórios; a campanha que vinha sendo desenvolvida contra o tracoma, e outras que não há [como] negar, provam que os técnicos nacionais sempre que empregados em atividades justas obtêm resultados os mais favoráveis. A Saúde Pública tem fracassado sempre que, pretendendo ultrapassar os limites de sua capacidade, lança programas na tentativa de resolver problemas para os quais as soluçôes estão fora do alcance das técnicas propriamente médico-sanitárias (Idem, p. 122, grifos meus).

De qualquer modo, mantém-se firme na sua posição claramente desenvolvimentista e estabelece a distinção entre estado sanitário ou condição sanitária e a saúde propriamente dita:

[...] quando dizíamos que a Saúde Pública era ligada ao desenvolvimento, eles [os defensores da tese da saúde pública como salvação nacional] diziam que não era assim, pois os antibióticos e inseticidas tinham melhorado muito as condições de saúde, sem que houvesse desenvolvimento [...]. De fato o que melhorava, muitas vezes, não era propriamente a saúde. A saúde continuava mais ou menos a mesma. O que melhorava era a situação sanitária, que não deve ser comparada a saúde. A situação sanitária pode melhorar sem nenhuma alteração da situação social das pessoas. Por exemplo: num país onde haja febre amarela, uma pessoa sofre de febre amarela porque tem o Aedes aegypti para transmitir a doença. Se se faz uma campanha e se elimina o Aedes aegypti, melhora-se o estado sanitário, mas a saúde das pessoas continua a mesma, porque elas continuam sem ter o que comer, dormindo mal etc. Então, não é a mesma coisa (Idem, p. 89). 
21. Além da polarização "desenvolvimento econômico-social como pré-requisito para o avanço da saúde" versus "açōes sanitárias como prioritárias para impulsionar o desenvolvimento", Farley aponta duas outras clivagens típicas do debate no período: campanhas verticais versus ações horizontais de saúde; subdesenvolvimento como condição intrínseca de um sistema internacional que o perpetua em favor dos países desenvolvidos versus a ideia de desenvolvimento como uma possibilidade para todos os países (apud Lima, Fonseca e Hochman, 2005, pp. 49-50).
Em outro momento, em consonância com as diretrizes da Organização Mundial da Saúde (oms), afirma o seguinte:

O homem tem necessidades que são anteriores às de ordem médico-sanitária, as consideradas necessidades fundamentais: alimentação, habitação ou abrigo e vestuário. Sem atendimento destas necessidades a utilização das conquistas médicas poderá resolver um grande número de problemas, inclusive conservar a vida; não dará, entretanto, saúde, porque saúde é muito mais do que a simples ausência de doença (Idem, p. 62).

Em verdade, como apontam Lima, Fonseca e Hochmam (2005), o tema do desenvolvimentismo era parte inescapável da agenda do período. Assim, embora com diferenças inegáveis, as diversas posições eram muito complexas e multifacetadas para comportarem uma visão absolutamente polarizada, sendo a imagem de um pêndulo, conforme sugere o historiador inglês John Farley ${ }^{21}$, que oscila em uma ou em outra direção - ora mais desenvolvimentista, ora mais próxima de uma concepção que privilegia as ações sanitárias na relação saúde/desenvolvimento -, a mais adequada para dar conta dos sentidos e direções atribuídos ao círculo vicioso pobreza/doença. De acordo com Lima, Fonseca e Hochman,

[...] ao longo do período de 1945-1964, todos os pronunciamentos oficiais e as posições políticas no campo da saúde pública associavam saúde e doença aos problemas do desenvolvimento e da pobreza. Não havia retórica contrária a essa constatação, repetidas inúmeras vezes por presidentes e ministros. As divergências e conflitos ocorriam em torno do entendimento sobre as relaçôes causais e sobre as estratégias politicas e institucionais de superação da doença e do subdesenvolvimento (Lima, Fonseca e Hochman, 2005, p. 49 , grifo meu).

"Nadar, nadar e morrer na praia": considerações finais

Segundo Sarah Escorel, Mário Magalhães foi, "por mais de vinte anos, o principal mentor do pensamento anti-hegemônico do sanitarismo desenvolvimentista", exercendo "papel fundamental na explicitação das novas propostas e, a partir de 1953, com a criação do Ministério da Saúde, passou a colaborar diretamente com os ministros da pasta" (Escorel, 2000, p. 96). De fato, dois aspectos, entre tantos, chamam a atenção nas narrativas que mencionam a atuação do sanitarista entre 1945 e 1964: 1) sua proximidade com autoridades políticas importantes do campo da saúde nesse momento, exercendo papel 
de interlocutor ativo de ministros da Saúde, elaborando planos e escrevendo discursos ${ }^{22}$; 2) sua autoridade e liderança "inconteste", como ressalta Escorel, em relação a outros sanitaristas do período, podendo ser visto como um catalisador de expectativas e projetos de mudança. Entretanto, apesar do lugar proeminente de Magalhães, suas teses e as do grupo que o cercava nunca se tornaram exatamente hegemônicas, de modo a se impor sobre as perspectivas mais propriamente campanhistas, ainda que tais concepções comportassem, como buscamos mostrar, certos níveis de mediação e interlocução entre elas, além de não apresentarem tanta unidade e identidade de princípios como se supunha (no caso das perspectivas sespiana e do campanhismo, por exemplo). Como recorda o próprio sanitarista, referindo-se à mensagem de Vargas ao Congresso Nacional em 1951, em um registro aliás bastante pessimista que, com certeza, não era bem o que ele tinha em mente no próprio momento de tais acontecimentos, "Getúlio aceitou nossas teses no discurso, mas as forças da inércia eram muito poderosas e tudo continuou na mesma, como continuaria até 1964" (Magalhães, apud Silva e Morell, 2008, p. 88).

De qualquer modo, pode-se dizer que Magalhães - cavaleiro andante da saúde pública, como sugere carinhosamente Francisco de Oliveira - foi um ator-chave das disputas da saúde desde pelo menos o final dos anos de $1940 \mathrm{e}$, se "viver é influenciar", como ele disse certa vez, buscou, em defesa das ideias em que acreditava de modo muito apaixonado, exercer sempre que pôde alguma influência. Precisamente no início dos anos de 1960, quando Mário e seu grupo assumiram a direção da conservadora Sociedade Brasileira de Higiene, em fins de 1962, o sanitarista se tornou secretário geral da III Conferência Nacional de Saúde, em 1963, e encontrou no ministro da Saúde, Wilson Fadul ${ }^{23}$ e no governo trabalhista de João Goulart verdadeiros parceiros na realização de reformas estruturais no país, parecia que suas teses desenvolvimentistas, de fato, iriam emplacar, o que pode ser observado até mesmo na citada III Conferência Nacional de Saúde, quando, de modo bastante confiante, Mário fala em nome do Ministério da Saúde e da "política geral do governo": "O Ministério da Saúde, dentro da política geral do Governo, reconhece que a saúde de uma população é uma consequência do desenvolvimento da economia nacional e da maior quantidade de bens e serviços que sejam postos à disposição da população e da possibilidade que esta tenha de usá-los, inclusive, é claro, os serviços médico-sanitários" (Idem, p. 146).

Entretanto, justamente quando o pêndulo parecia oscilar na direção mais favorável aos ventos da mudança e dos ideais mais nitidamente desenvolvimentistas e reformistas na saúde, efetivamente "posta a serviço do povo", nos
22. Ver nota 15 .

23. De acordo com Fausto Silveira (apud Escorel, 2000, p. 96), Aramis Athayde e Wilson Fadul "tinham as mesmas ideias do Mário e seu grupo". 
termos de Magalhães (Idem, p. 150), ou seja, quando o seu grupo de sanitaristas, palavras de Mário, sentiu que "havia chegado o momento de transformar [...], de implantar [...] outro plano, outra política de Saúde Pública no Brasil” (Idem, p. 90), veio o golpe civil militar de 1964 para interromper esse ambicionado processo. E concluiu um tanto desolado: "é o mesmo que o sujeito náufrago nadar, nadar e morrer na praia" (Idem, p. 93).

Infelizmente, parece que Magalhães, nesse caso, tinha plena razão e, de fato, tais ideais naquele momento acabaram por morrer na praia. No entanto, delícias e agruras da história, em outros momentos, podem servir para mobilizar desejos e reinventar projetos temporariamente derrotados, como parece ser a apropriação interessada que o movimento sanitário dos anos de 1970 e 1980 buscou fazer do importante legado do sanitarismo desenvolvimentista, tendo em vista seus importantes objetivos reformistas na saúde, ainda que com certo prejuízo de uma leitura mais plural da história.

\section{Referências Bibliográficas}

Bielschowsky, Ricardo. (2009), "Ideologia e desenvolvimento (Brasil 1930-1964)”. In: PÁdua, José Augusto (org.). Desenvolvimento, justiça e meio ambiente. Belo Horizonte/São Paulo, Editora da UFMG/Peirópolis, pp. 22-63.

Braga, José Carlos de Souza \& Paula, Sergio Goes de. (1981), Saúde e previdência: estudos de política social. São Paulo, Cebes/Hucitec.

Campos, André Luiz Vieira de. (2006), Politicas internacionais de saúde na era Vargas: o Serviço Especial de Saúde Pública. Rio de Janeiro, Editora Fiocruz.

. (2000), "Políticas internacionais de saúde na era Vargas: o Serviço Especial de Saúde Pública”. In: Gomes, Angela de Castro (org.). Capanema: o ministro e seu ministério. Rio de Janeiro, Editora FGV, pp. 195-220.

Costa Filho, David Capistrano da. (1978), "A falsidade do círculo vicioso da pobreza e da doença”. Saúde e Debate, 6: 65-66.

Cunha, Neiva Vieira da. (2005), Viagem, experiência e memória: narrativas de profissionais da Saúde Pública dos anos 30. Bauru, SP, Edusc.

Escorel, Sarah. (2000), Saúde pública: utopia de Brasil. Rio de Janeiro, Relume Dumará/Prefeitura.

FARIA, Lina. (2007), Saúde epolitica: a Fundação Rockefeler e seus parceiros em São Paulo. Rio de Janeiro, Editora Fiocruz.

Fonseca, Cristina Oliveira M. (2001), "As campanhas sanitárias e o Ministério da Saúde (1953-60)". In: BenCHIMOL, Jaime L. (coord.). Febre amarela: a doença e a vacina, uma história inacabada. Rio de Janeiro, Editora Fiocruz, pp. 299-305. 
. (2007), Saúde no governo Vargas (1930-45): dualidade institucional de um bem público. Rio de Janeiro, Editora Fiocruz.

Fonseca, Pedro César Dutra. (2012), "Gênese e precursores do desenvolvimento no Brasil”. In: Bastos, Pedro Paulo Zahluth \& Fonseca, Pedro César Dutra (orgs.). A era Vargas: desenvolvimentismo, economia e sociedade. São Paulo, Editora da Unesp, pp. 21-49.

Furtado, Celso. (1987), "A luta continua! Uma palavra nunca posta em dúvida porque não servia a nada além da verdade”. Saúde em Debate, 19: 148-149.

Gomes, Angela de Castro. (1999), Essa gente do Rio... Modernismo e nacionalismo. Rio de Janeiro, Editora FGV.

Hochman, Gilberto. (2001), “A saúde pública em tempos de Capanema: continuidade e inovações”. In: Bomeny, Helena (org.). Constelação Capanema: intelectuais e políticas. Rio de Janeiro, Editora FGV, pp. 127-151.

. (2009), "O Brasil não é só doença; o programa de saúde pública de Juscelino Kubitschek”. História, Ciências, Saúde, Manguinhos, 12: 313-331.

Lima, Nísia Trindade; Fonseca, Cristina M. O. \& Hochman, Gilberto. (2005a), "A saúde na construção do Estado nacional no Brasil: reforma sanitária em perspectiva histórica”. In: Lima, Nísia Trindade et al. (orgs.). Saúde e democracia: história e perspectivas do sus. Rio de Janeiro, Editora Fiocruz, pp. 27-58.

Luz , Madel T. (1979), As instituiçôes médicas no Brasil: instituiçôes e estratégias de hegemonia. Rio de Janeiro, Graal.

Mello, Guilherme Arantes. (2010), Revisão do pensamento sanitário com foco no centro de Saúde. Tese de doutorado. São Paulo, fmusp.

Oliveira, Francisco de. (1987), "A luta continua! Mário Magalhães: o sacerdócio obsessivo em favor da causa do serviço público". Saúde em Debate, 19: 147-148.

PAIva, Carlos Henrique Assunção. (2004), "A saúde pública no Brasil do pós-guerra: sob o paradigma da ideologia do desenvolvimentismo (1950-1980)". Anais do XXVIII Encontro Anual da Anpocs. São Paulo, Anpocs.

Silva, Rebeca de Souza \& Morell, Maria Graciela G. de (orgs.). (2008), Política nacional de saúde pública. A trindade desvelada: economia-saúde-população. 2. ed. Rio de Janeiro, Revan.

Teixeira, Sonia M. Fleury (org.). (1988), “Antecedentes da Reforma Sanitária”. Rio de Janeiro, Ensp-Fiocruz (relatório de pesquisa).

WinsLow, Charles-Edward Amory. (1955), Lo que cuesta la enfermedady lo que vale la salud. Washington, Oficina Sanitária Panamericana/oms (Serie de Monografías, n. 7). 


\footnotetext{
* Este texto resulta de um projeto mais amplo, financiado pelo CNPq, intitulado "Caminhos e percalços da saúde no Brasil: uma análise sobre os discursos de reforma sanitária no século $\mathrm{xx}$ ". Envolve pesquisadores de três instituições: a Escola Nacional de Saúde Pública (Ensp-Fiocruz), a Escola Politécnica de Saúde Joaquim Venâncio (EPSJV-Fiocruz) e o Instituto de Medicina Social (IMs-Uerj). Agradeço a Tatiana Wargas, Ruben Mattos, Monica de Rezende, Arthur Lobo Mattos e José Vítor Regadas, pelas importantes e prazerosas discussões sobre o tema, e sobretudo a Camila Furlanetti Borges, por suas valiosas contribuições no deslindamento das instigantes ideias do sanitarista Mário Magalhães.
}

Texto enviado em 24/3/2014 e aprovado em 24/3/2015.

DOI: http://dx.doi.org/10. 1590/0103-20702015213

José Roberto Franco Reis é doutor em história social pela Universidade Estadual de Campinas (Unicamp) e pesquisador da Escola Politécnica de Saúde Joaquim Venâncio da Fundação Oswaldo Cruz (EPsjv-Fiocruz). E-mail: zeroberto@fiocruz.br.

\section{Resumo}

"Viver é influenciar: Mário Magalhães, sanitarismo desenvolvimentista e o campo intelectual da saúde pública (1940-1960)

O artigo se debruça sobre o pensamento sanitário brasileiro entre os anos de 1940 e 1960 com o objetivo de refletir sobre a relação entre saúde e desenvolvimento. Busca, assim, problematizar a compreensão corrente que identifica um processo de polarização aberta entre os modelos de saúde consolidados no primeiro governo Vargas, notadamente as políticas do dito sanitarismo campanhista e do Serviço Especial de Saúde Pública (Sesp), em contraposição ao que se convencionou chamar sanitarismo desenvolvimentista, organizado sobretudo a partir dos anos de 1950 . Os primeiros se caracterizariam pela crença de que elevados investimentos em saúde poderiam resolver os problemas sanitários, além de propiciar crescimento e prosperidade; o segundo, pela ideia de que o desenvolvimento econômico da nação seria precondição para a melhora da situação geral da saúde. Para tanto, o autor se vale das formulações do sanitarista brasileiro Mário Magalhães, identificado no texto como um dos nomes mais representativos da corrente intelectual desenvolvimentista no campo da saúde.

Palavras-chave: Sanitarismo desenvolvimentista; História da saúde pública; Sanitarismo campanhista; Mário Magalhães; Pobreza, doença e desenvolvimento.

\section{Abstract}

"To live is to influence": Mário Magalhães, developmental sanitarism and the intellectual field of public health (1940-1960)

This paper aims to look into the Brazilian health thinking between the decades of 1940 and 1960, with the major goal of reflecting on the relationship between health and development. Therefore, we discuss the current understanding that recognizes an open polarization process between the models of health consolidated on the 1st Vargas Government, notably the policies of the sanitarist-campaign and the Special Service Public Health (Sesp), in contrast to the developmental-sanitarism, organized mainly during the ' 50 s onwards. The first one would be characterized by the belief that a high amount of health investments could solve health problems, improving growth and prosperity in addition. On the contrary, the developmental-sanitarism holds the idea that it would be essential to develop economically the nation as a precondition for improving the overall health status. In this attempt, we make use of Mário Magalhães formulations, a Brazilian sanitarist observed here as one of the most important names of the intellectual developmental school in health.

Keywords: Developmental-sanitarism; History of public health; Sanitarist campaign; Mário Magalhães; Disease, poverty and development. 